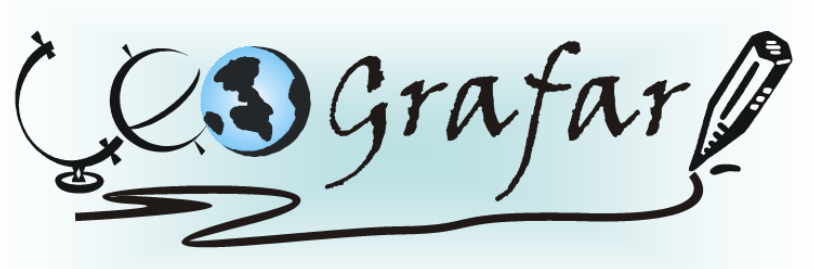

Revista Eletrônica do Programa de Pós-Graduação em Geografia - UFPR

\title{
PROPRIEDADES MORFOMÉTRICAS DA BACIA HIDROGRÁFICA DO CÓRREGO MARUMBIZINHO, JANDAIA DO SUL/PR
}

\author{
ÉDERSON DIAS DE OLIVEIRA ${ }^{1}$ \\ VICTOR ASSUNÇÃO BORSATO
}

\begin{abstract}
RESUMO
O presente trabalho apresenta a caracterização morfométrica da Bacia Hidrográfica do Córrego Marumbizinho - Jandaia do Sul/PR. O Córrego Marumbizinho percorre um trecho de $5,3 \mathrm{~km}$, possui uma área de drenagem de $7,82 \mathrm{~km}^{2}$, uma hierarquização fluvial de $3^{\text {a }}$ ordem, densidade de drenagem de $2,07 \mathrm{~km} / \mathrm{km}^{2}$, amplitude topográfica de 219 metros e conta com parte da porção montante da sua bacia ocupada pela área urbana de Jandaia do Sul/PR. Estudos envolvendo os aspectos físicos da Bacia Hidrográfica do Córrego Marumbizinho são escassos. O estudo foi efetivado por meio do levantamento de dados bibliográfico-cartográficos e levantamento de campo. Para a manipulação dos dados foram empregados os softwares Spring e a planilha eletrônica Calc., sendo analisada uma série de parâmetros morfométricos da bacia hidrográfica. A área apresenta declividades acentuadas principalmente no entorno das nascentes que associados aos elevados índices pluviométricos da região e a área urbana favorecem processos de movimento de massa nas encostas e deposição de materiais tecnogênicos nos fundos do vale. A bacia é importante para a cidade haja vista ser a principal fonte de captação d"água para o abastecimento urbano. Dessa maneira o uso do solo deve ser planejado afim de não comprometer a qualidade da água e o regime fluvial da bacia hidrográfica.
\end{abstract}

Palavras Chave: Rede de Drenagem. Hidrogeomorfologia. Morfometria. Bacia Hidrográfica.

\footnotetext{
${ }^{1}$ Mestrando em Geografia - Universidade Estadual do Centro Oeste (UNICENTRO); e-mail: edersonjandaia@hotmail.com

${ }^{2}$ Professor Doutor do Departamento de Geografia - Faculdade de Jandaia do Sul (FAFIJAN); e-mail: victorborsato@yahoo.com.br
} 


\title{
MORPHOMETRIC PROPERTY OF MARUMBIZINHO STREAM WATERSHED, JANDAIA DO SUL/PR.
}

\begin{abstract}
The present work introduces the morphometric characterization of the watershed of Marumbinho river - Jandaia do Sul / PR. The stream runs through a stretch of Marumbizinho 5,3 km, has a drainage area of 7,82 square kilometers, a ranking of 3rd order river, drainage density of $2.07 \mathrm{~km} / \mathrm{km}^{2}$, width of $219 \mathrm{~m}$ and topographic features part amount of its portion of the basin occupied by the urban area of South Jandaia / PR. Studies of the physical aspects of the Basin Creek Marumbizinho are scarce. The study was based in bibliographical and map data and fieldwork in the study area. For the data manipulation were used the Spring software and Calc spreadsheet, being analyzed a series of morphometric parameters of the watershed. The area has steep slopes especially in the surroundings of the springs that associated with high rainfall in the region and promotethe urban mass movement processes on the slopes and deposition of materials tecnogenic in the valley bottoms. The basin is important for the city has seen to be the main funding source water for urban supply. Thus the land use must be plannedso as not to compromise the water quality of river and watershed.
\end{abstract}

Keywords: drainage network, Hydrogeomorphology, watershed

\section{INTRODUÇÃO}

$\mathrm{Na}$ atualidade os enfoques dos trabalhos ambientais têm levado em consideração a necessidade premente da conservação dos solos, da diminuição dos impactos urbanos, da produção de energia entre outras ações, a fim de tornar o uso dos recursos naturais mais sustentáveis. Neste contexto, segundo Oliveira et. al. (2010) a bacia hidrográfica $(\mathrm{BH})$ tem sido amplamente utilizada como recorte espacial nos estudos geográficos, sendo que vários autores apontam esta como uma unidade ambiental que possibilita tratar dos componentes e da dinâmica das inter-relações necessárias ao planejamento e a gestão ambiental.

No Brasil, a Lei Federal № 9.433, que estabeleceu a Política Nacional de Recursos Hídricos, institui a bacia hidrográfica $(\mathrm{BH})$ como unidade territorial de planejamento e gestão dos recursos hídricos (BRASIL, 1997).

$\mathrm{A} B \mathrm{BH}$ é constituída pelo conjunto de vertentes drenado por um rio ou por um sistema de drenagem. Ela é um sistema aberto com entrada de energia (ciclo 
hidrológico) e com exportação de matéria (água, solutos, sedimentos etc.). Os variados tipos de uso do solo acarretam profundas transformações na dinâmica dos processos hidrogeomorfológicos como: poluição das águas, sedimentação, erosão fluvial, mudança de regime hidrológico, mudança no ecossistema fluvial, etc. (THOMAZ, 2007).

Contudo, além de conceituar a BH, e definir suas aplicabilidades é necessária uma caracterização dos seus principais aspectos fisiográficos, a fim de facilitar os estudos que tenham a $\mathrm{BH}$ como recorte espacial. Portanto, a caracterização morfométrica é um dos primeiros e mais comuns procedimentos executados em análises hidrológicas ou ambientais, e tem como objetivo elucidar as várias questões relacionadas no entendimento da dinâmica ambiental local e regional (TEODORO et. al. 2007). Pois os aspectos físicos e bióticos da bacia desempenham importante papel nos processos do ciclo hidrológico, influenciando dentre outros, a evapotranspiração, a infiltração e quantidade de água produzida como deflúvio e os escoamentos superficial/subsuperficial (TONELLO, 2005).

Cabe destacar também que nas últimas décadas as ações antrópicas com destaque para a expansão urbana têm acelerado e potencializado alterações nas características morfométricas da $\mathrm{BH}$, por meio da canalização e retilinização de cursos fluviais, terraplanagem, impermeabilização do solo e etc.

O presente trabalho tem como área de estudo a Bacia Hidrográfica do Córrego Marumbizinho (BHCM). A análise dos aspectos naturais dessa área é de grande significância, pois ela fornece a água que abastece a cidade de Jandaia do Sul, além de ter uma grande porção no entorno das nascentes ocupado pela área urbana da cidade. Dessa maneira, têm sido potencializados impactos socioambientais tais como: lançamentos de efluentes, sólidos e líquidos pelos moradores do entorno, o surgimento ravinamentos nos solos das vertentes em função do escoamento pluvial. Há terminais de galerias pluviais no córrego, grandes áreas de pavimentação urbana, cujo escoamento pluvial destina-se ao córrego.

Trata-se de problemas ambientais advindos de um planejamento que atende as necessidades imediatas e não visam às questões ambientais. A intensa urbanização, verificada a partir da década de 1970 gerou aumento de pressão antrópica na área. Portanto, o presente trabalho objetiva analisar e caracterizar os 
aspectos morfométricos da BHCM. Dessa maneira, serão estimados vários índices morfométricos como a área da $\mathrm{BH}$, a densidade de drenagem, o perfil longitudinal do canal principal, a curva hipsométrica e clinográfica, o mapeamento das declividades e das altitudes. Por meio da análise desses dados, será possível entender um pouco mais da dinâmica hidrogeomorfológica da BHCM, e contribuir no seu manejo e planejamento.

\section{MATERIAIS E MÉTODOS}

\section{1 ÁREA DE ESTUDO}

A BHCM localiza-se na região centro-norte do Estado do Paraná, no município de Jandaia do Sul, sendo delimitada pelos paralelos $23^{\circ} 36^{\prime} 10^{\prime \prime}$ e $23^{\circ} 38^{\prime}$ $30^{\prime \prime}$ de latitude sul e os meridianos $51^{\circ} 36^{\prime} 34^{\prime \prime}$ e $51^{\circ} 38^{\prime} 49^{\prime \prime}$ de longitude oeste (Gw) (FIGURA 1).

A BHCM ocupa uma área aproximada de $7,82 \mathrm{~km}^{2}$ sendo o canal principal o córrego Marumbizinho, que integra o sistema hidrográfico da bacia do rio Ivaí. Embora o córrego Marumbizinho seja um pequeno rio, o mesmo mantém um regime perene, sendo que no inverno se verifica o menor volume de água e janeiro/fevereiro a maior, sendo essa variação em função do clima da região. Segundo a classificação de Koeppen a tipo climático predominante na área é o subtropical mesotérmico úmido, com média do mês mais quente superior a $2^{\circ}{ }^{\circ} \mathrm{C}$, e do mês mais frio inferior a $1^{\circ} \mathrm{C}$, sem estação seca definida, verão quente e geada pouco freqüente (MAACK, 2002).

Os resquícios de vegetação da área expressam à ação do clima em relação à latitude, a altitude e a natureza do solo. A boa distribuição pluviométrica, em quase todos os meses do ano, contribui para desenvolvimento da floresta Estacional Semidecidual. Esta se caracteriza por árvores que atingem até 30 metros de altura, sem formar cobertura superior contínua (MIKICH e SILVA, 2001). No entanto, devido à dizimação impostas pelo homem, atualmente são raros os locais do município onde subsistem remanescentes da vegetação original da região, estando à cobertura 
florestal primitiva mais significativa restrita a trechos de mata ciliar ao longo dos cursos d'água e algumas manchas esparsas de floresta.

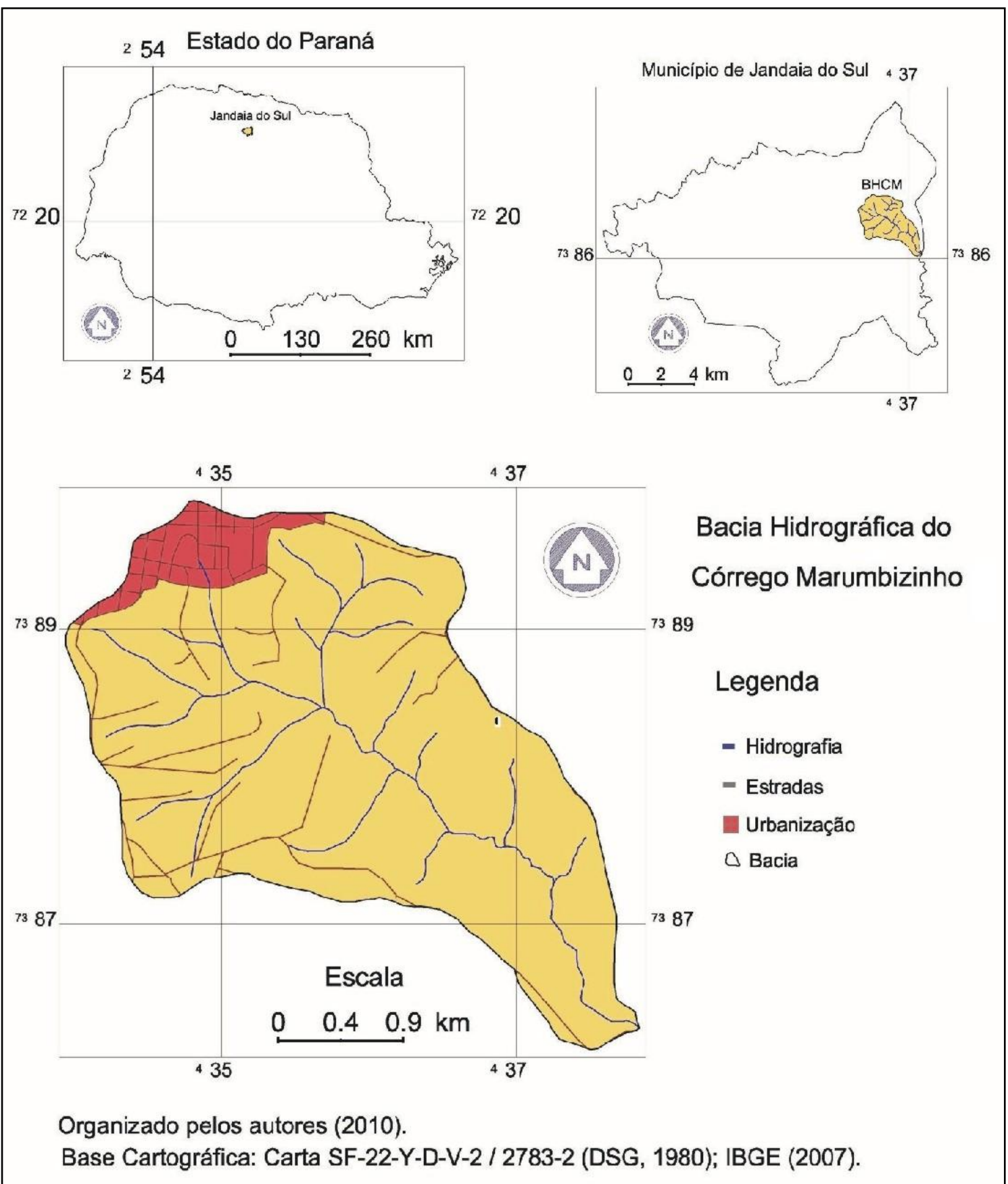

FIGURA 1 - LOCALIZAÇÃO DA BACIA HIDROGRÁFICA DO CÓRREGO MARUMBIZINHO 
Quanto à base geológica a bacia está assentada sobre o manto de rochas basálticas da Formação Serra Geral, Grupo São Bento, que se caracteriza por apresentar rochas efusivas básicas toleíticas com basaltos maciços e amigdalóides e de textura afaníticos, cinzentos a pretos, raramente andesíticos, advindos de derrames de vulcanismo de fissura continental (IBGE, 2006).

\subsection{PROCEDIMENTOS METODOLÓGICOS}

Os procedimentos metodológicos adotados foram um breve levantamento bibliográfico, sem querer esgotar o assunto e trabalho de campo complementado pelo de gabinete:

I) Revisão bibliográfica: etapa da pesquisa onde se buscou uma fundamentação teórica para o levantamento das propriedades morfométricas, por meio de pesquisas em variadas fontes bibliográficas.

II) Trabalho de campo/gabinete: nesta etapa foram realizados perfis no sentido transversal e longitudinal do canal fluvial principal. Os dados cartográficos foram trabalhados no Laboratório de Hidrogeomorfologia (LabHidro) da UNICENTRO (Universidade Estadual do Centro-oeste) utilizando-se de técnicas de Geoprocessamento.

A base cartográfica utilizada foi a Carta Topográfica de Mandaguari: SF-22Y-D-V-2 / 2783-2; Projeção Transversal de Mercator (UTM); Meridiano Central: $51^{\circ}$ W. GR; Datum Planimetrico: SAD 69 - Minas Gerais; Eqüidistância das curvas de nível 20 metros; Escala 1:50.000; Diretoria de Serviço Geográfico do Exército, (DSG, 1980).

Os dados cartográficos foram integrados em um banco de dados geográficos, ou seja, em um SIG (Sistema de Informação Geográfica), utilizando-se do software SPRING - INPEC Versão 5.1.6 - Sistema de Processamento de Informações Georreferenciadas (Copyright), desenvolvido pela Divisão de Processamento de Imagens - DPI do Instituto Nacional de Pesquisas Espaciais (INPE). O uso dos SIG permite a entrada, o armazenamento, o tratamento, o processamento, a integração, a recuperação, a transformação, a manipulação, a modelagem, a atualização, a análise e a exibição de informações geográficas, 
topologicamente estruturadas, associados a um banco de dados alfanumérico (CÂMARA et. al., 1996).

Para a identificação e análise das principais propriedades fisiográficas da BHCM, teve-se como base os índices propostos nos trabalhos de Horton (1945), Chistofoletti (1980) e Oliveira et. al. (2010). A hierarquização fluvial de Strahler (1957) foi utilizada, por retirar a subjetividade existente nas outras formas de hierarquização. Dessa forma, por meio da planilha eletrônica Calc. do software BrOffice, foram estimados os seguintes índices morfométricos:

1) Área da $\mathrm{BH}(\mathrm{A})$ - dada em $\mathrm{km}^{2}$ numa projeção plana.

2) Perímetro da $\mathrm{BH}(\mathrm{P})$ - comprimento da linha imaginária ao longo do divisor de águas que delimita área da bacia hidrográfica $(\mathrm{km})$.

3) Comprimento total dos cursos fluviais ( $L t)$ - refere-se à soma de todos os comprimentos dos rios da $\mathrm{BH}(\mathrm{km})$.

4) Densidade de drenagem (Dd) - relação existente entre o comprimento total de todos os cursos fluviais da $\mathrm{BH}(\mathrm{Lt})$ e a área contribuinte $(\mathrm{A})$, sendo obtida pela equação: $\mathrm{Dd}=\mathrm{Lt} / \mathrm{A}$, em $\left(\mathrm{km} / \mathrm{km}^{2}\right)$.

5) Número total de segmentos (Nr) - número de segmentos fluviais em cada ordem, de acordo com a hierarquização de Strahler (1957).

6) Comprimento do canal fluvial principal ( $\mathrm{Rp}$ ) - comprimento do curso fluvial que possui a maior distancia iniciando pela foz e que se encontra dentro da $\mathrm{BH}(\mathrm{km})$.

7) Curva hipsométrica - gráfico que representa a distribuição do relevo de acordo com sua altitude, indicando a percentagem de área de drenagem que existe acima ou abaixo das várias altitudes.

8) Amplitude topográfica $(\mathrm{Hm})$ - diferença entre o ponto mais elevado da $\mathrm{BH}$ e a exutória do canal fluvial principal.

9) Perfil longitudinal do curso fluvial principal - modelo que relaciona a altitude em metros do canal fluvial com as suas distâncias representando o perfil longitudinal do rio principal da sua nascente até a exutória.

10) Declividade do canal principal (SRp) - relação $(\mathrm{m} / \mathrm{m})$ entre a Amplitude altimétrica do canal principal $(\Delta \mathrm{H})$ e o seu comprimento total $(\mathrm{Rp})$, sendo obtida pela equação: $S R p=\Delta H / R p$. 
11) Mapa clinográfico e hipsométrico: esses mapas fornecem elementos morfométricos, morfográficos e até dinâmico, e permitem a inferência de processos dominantes (escoamento, erosão, movimentos de massa entre outros) de acordo com a energia do relevo (TONELLO, 2005). Na elaboração do mapa clinigráfico foi adotado a proposta de Ross (1994), as classes de declividade (em percentagem) utilizadas foram: $<\rightarrow 6 ; 6 \rightarrow 12 ; 12 \rightarrow 20 ; 20 \rightarrow 30 ;>30$. Para o mapa hipsométrico foram estabelecidas 07 classes temáticas de altitude $(\mathrm{m})$ sendo: $590 \rightarrow 620 ; 620 \rightarrow$ $640 ; 640 \rightarrow 680 ; 680 \rightarrow 720 ; 720 \rightarrow 760 ; 760 \rightarrow 800 ;>-800$, distribuídas no intervalo de 590 a 810 metros.

12) Curva clinográfica: curva acumulativa da freqüência das classes de declividade, ou seja, indica a porcentagem que as classes acumuladas ocupam em relação à área total da $\mathrm{BH}$.

\section{RESULTADOS E DISCUSSÕES}

\subsection{ASPECTOS MORFOMÉTRICOS}

A rede de drenagem é um dos principais aspectos da $\mathrm{BH}$, estando relacionada não só com a pluviosidade e topografia, como também com a cobertura vegetal, o tipo de solo, a litologia e a estrutura das rochas (SUGUIU e BIGARELLA, 1990). Ao aplicar a proposta de hierarquização fluvial de Strahler (1957) na BHCM, esta foi classificada como de $3^{\text {a }}$ ordem.

O padrão de drenagem é do tipo dendrítica ou arborescente, de acordo com a classificação geométrica dos padrões de drenagem proposto por Suguiu e Bigarella (1990). Essa composição de padrões de drenagem na $\mathrm{BH}$ se deve ao desenvolvimento dos canais sobre rochas (basalto) com resistência uniforme, que condiciona o padrão arborescente, mostrado na figura 1. O canal fluvial principal apresenta uma declividade média expressiva com aproximadamente 35,85 m/km, com significativas declividades na porção montante do canal (FIGURA 2). 


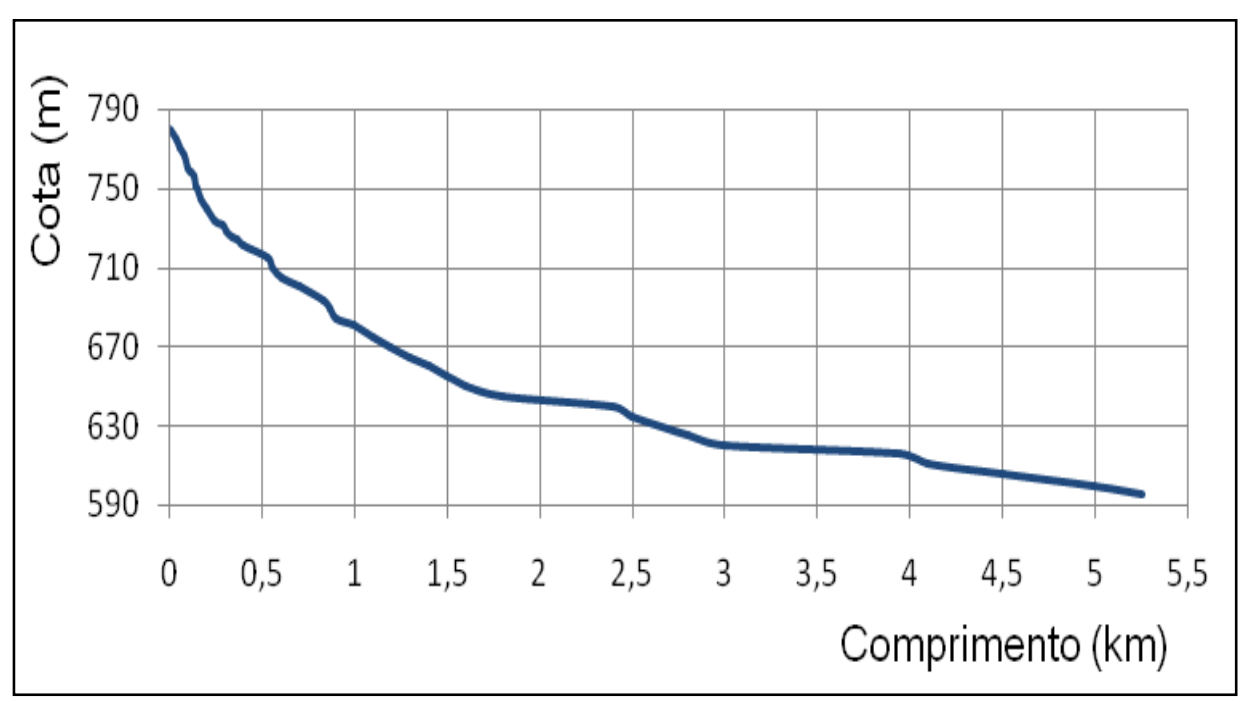

FIGURA 2 - MODELO DO PERFIL LONGITUDINAL DO CÓRREGO MARUMBIZINHO

FONTE: Os autores (2010)

Na tabela 1 são apresentados os resultados referentes aos parâmetros morfométricos da BHCM. O quociente da área da bacia, que é de aproximadamente $7,82 \mathrm{~km}^{2}$ com o do comprimento dos cursos fluviais, que é de $16,20 \mathrm{~km}$ resultou numa densidade de drenagem de 2,07 km/ $/ \mathrm{km}^{2}$. Dessa forma pode-se afirma que 0 índice encontrado condiciona uma significativa densidade de drenagem e baixa transmissibilidade, ou seja, o terreno apresenta um moderado grau de infiltração, tomando como base à proposição de Villela e Mattos (1975), na qual a densidade varia de pobre $\left(0,5 \mathrm{~km} / \mathrm{km}^{2}\right)$ a bem drenada $\left(>3,5 \mathrm{~km} / \mathrm{km}^{2}\right)$. Para Milani e Canali (2000), a densidade de drenagem reflete a propriedade de transmissibilidade do terreno e, consequentemente, a suscetibilidade a erosão. 
TABELA 1 - ÍNDICES MORFOMÉTRICOS DA BHCM

\begin{tabular}{lcc}
\hline \multicolumn{1}{c}{ Índices } & Valores & Unidade \\
\hline Área (A) & 7,82 & $\mathrm{~km}^{2}$ \\
Perímetro $(\mathrm{P})$ & 12,75 & $\mathrm{~km}$ \\
Comprimento total dos cursos fluviais & 16,20 & $\mathrm{~km}$ \\
(Lt) & 2,07 & $\mathrm{~km} / \mathrm{km}^{2}$ \\
Densidade de drenagem (Dd) & 5,30 & $\mathrm{~km}$ \\
Comprimento do rio principal (Rp) & 35,85 & $\mathrm{~m} / \mathrm{km}$ \\
Declividade do canal Principal (SRp) & 219 & $\mathrm{~m}$ \\
Amplitude topográfica (Hm) & 2,17 & - \\
Densidade de rios (Dr) & 1,28 & - \\
Coeficiente de compacidade (Kc) & 0,35 & - \\
Fator de Forma (F) & & \\
\hline
\end{tabular}

FONTE: Os autores (2010)

O fator de forma e o coeficiente de compacidade são os parâmetros morfométricos mais utilizados para verifica-se se a BH é suscetível a inundação, por influenciar no tempo de concentração da bacia. Para Villela e Mattos (1975) o fator de forma demonstra uma relação da bacia com um retângulo e também indica a maior ou menor probabilidade de enchentes, já o coeficiente de compacidade demonstra a proximidade da forma da BH com um círculo.

O fator de forma da BHCM é de 0,35 indicando que a forma da bacia, de modo geral, não favorece a concentração do fluxo fluvial, ou seja, permite que os fluxos dos tributários cheguem a exutório da bacia em tempos diferentes, com o início da chuva. Analogamente ao fator forma, o coeficiente de compacidade da bacia foi de 1,28 , indicando que a forma da bacia distancia-se da forma circular.

\subsection{ASPECTOS HIPSOMÉTRICOS}

Os indicadores hipsométricos possibilitam estudar as inter-relações existentes em determinada unidade horizontal de espaço no tocante a sua distribuição em relação às faixas altitudinais, indicando a proporção ocupada por determinada isoípsa base (CHRISTOFOLETTI, 1980). 
A figura 3 apresenta a Curva Hipsométrica da BHCM, onde se observa a distribuição do relevo. A linha vermelha representa a altitude mediana de $705 \mathrm{~m}$, enquanto que a linha verde representa à altitude média de $690 \mathrm{~m}$ da $\mathrm{BH}$. Para Oliveira et. al. (2010) nos estudos hidrológicos a média pode não ser representativa do universo da pesquisa, pois a mesma pode ser influenciada por valores extremos, dessa forma é usual também representar à mediana, sendo esta menos sensível a valores extremos se comparado com a média.

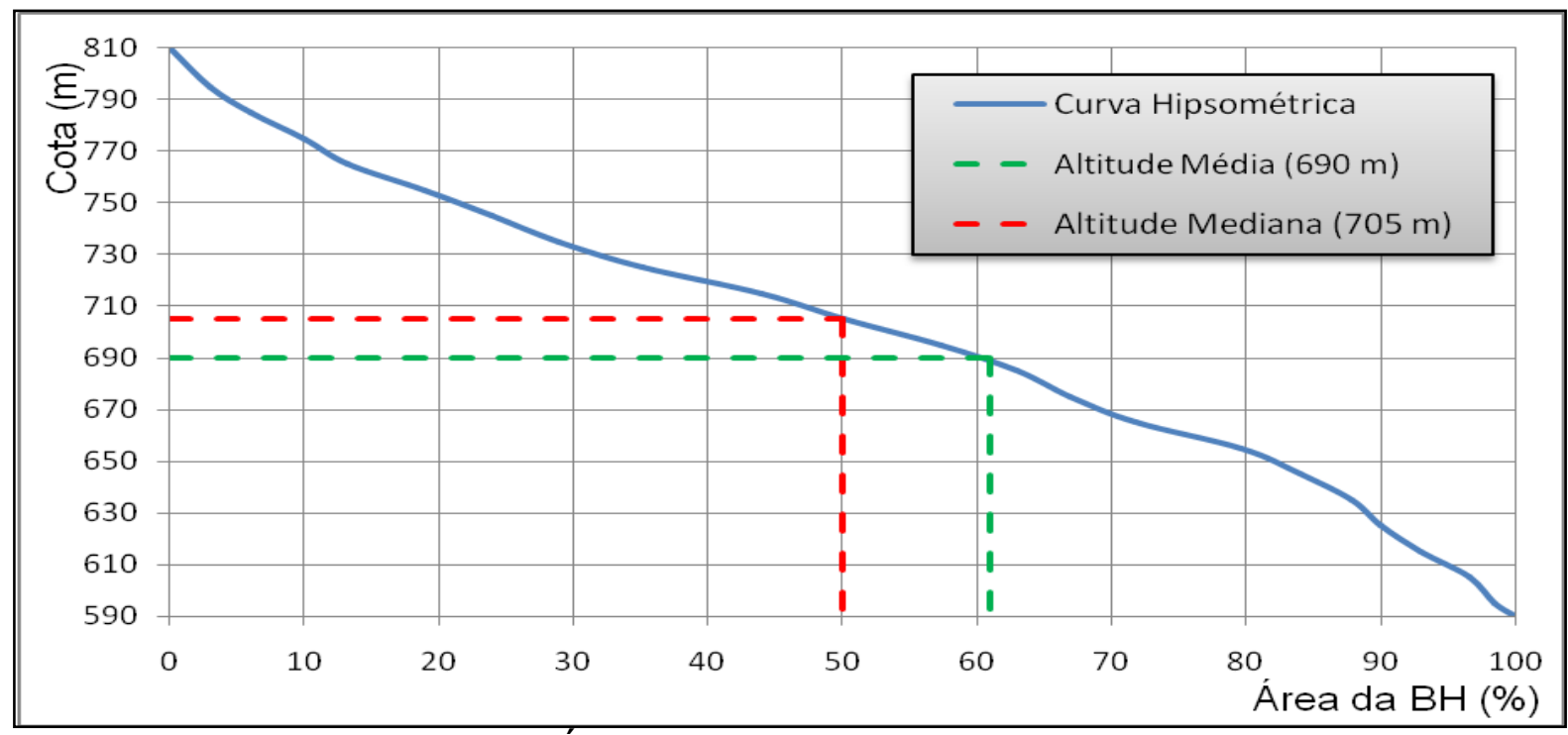

FIGURA 3 - CURVA HIPSOMÉTRICA DA BHCM

FONTE: Os autores (2010)

A amplitude topográfica $(\mathrm{Hm})$ é facilmente visualizada na curva hipsométrica, que possui a maior altitude em 809 metros e a menor com 590 metros, sendo a diferença desses dois extremos a $\mathrm{Hm}$ da bacia, ou seja, 219m. A definição desse índice é essencial para a caracterização da $\mathrm{BH}$, pois a amplitude do relevo influencia na temperatura, na perda de água que ocorrem pela evapotranspiração e também na perda de volume de material da bacia (o que foi erodido) pelo entalhamento do canal.

A variação da precipitação tem relação com a $\mathrm{Hm}$, assim com a dinâmica do escoamento superficial, da infiltração, do tempo de concentração e o deflúvio médio (Vilella e Mattos, 1975). Quanto à variação da temperatura em relação à altitude, Fritzsons et. al., (2008) após analisar as séries históricas das estações 
meteorológicas do Paraná definiu o gradiente térmico do Estado em 126 metros. Esse se refere à média do mês de janeiro considerando todas as estações metereológicas do Paraná (excluindo as do litoral), ou seja, há uma diminuição média de $1^{\circ} \mathrm{C}$ a cada 126 metros de altitude no Estado. Portanto, pode-se considerar que a BHCM possui uma significativa amplitude altimétrica (219 metros) que influencia na temperatura e outros processos meteorológicos derivados.

Com relação às classes altimétricas, a BHCM tem o relevo bem distribuído com a maioria das classes altimétricas bem representadas (TABELA 2 e FIGURA 4).

TABELA 2 - CLASSES ALTIMÉTRICAS DA BHCM

\begin{tabular}{cccc}
\hline $\begin{array}{c}\text { Classe altimétrica } \\
(\mathrm{m})\end{array}$ & $\begin{array}{c}\text { Área em cada } \\
\text { classe }\left(\mathrm{km}^{2}\right)\end{array}$ & $\begin{array}{c}\text { Percentual } \\
\text { por classe }\end{array}$ & $\begin{array}{c}\text { Percentual } \\
\text { acumulado }\end{array}$ \\
\hline $590-620$ & 0,31 & 3,96 & 3,96 \\
$620-640$ & 1,39 & 17,77 & 21,73 \\
$640-680$ & 1,65 & 21,1 & 42,83 \\
$680-720$ & 1,77 & 22,63 & 65,46 \\
$720-760$ & 1,69 & 21,62 & 87,08 \\
$760-800$ & 0,98 & 12,53 & 99,61 \\
$>-800$ & 0,03 & 0,39 & 100,00 \\
Total & 7,82 & 100,00 & 100,00
\end{tabular}

FONTE: Os autores (2010)

$\mathrm{Na}$ BHCM foram traçados cinco perfis transversais, onde se pode observar o predomínio de vertentes convexas na porção superior da bacia e vertentes côncavas/retilíneas na porção inferior (FIGURAS 4 e 5). Com exceção do perfil E, todos os perfis apresentaram declividades expressivas que condiciona significativas energias ao fluxo e processos erosivos. Ainda é possível observar a presença de vales em $\mathrm{V}$ e $\mathrm{U}$, além da drenagem que se associa à evolução geodinâmica e ao forte condicionamento morfoestrutural. 


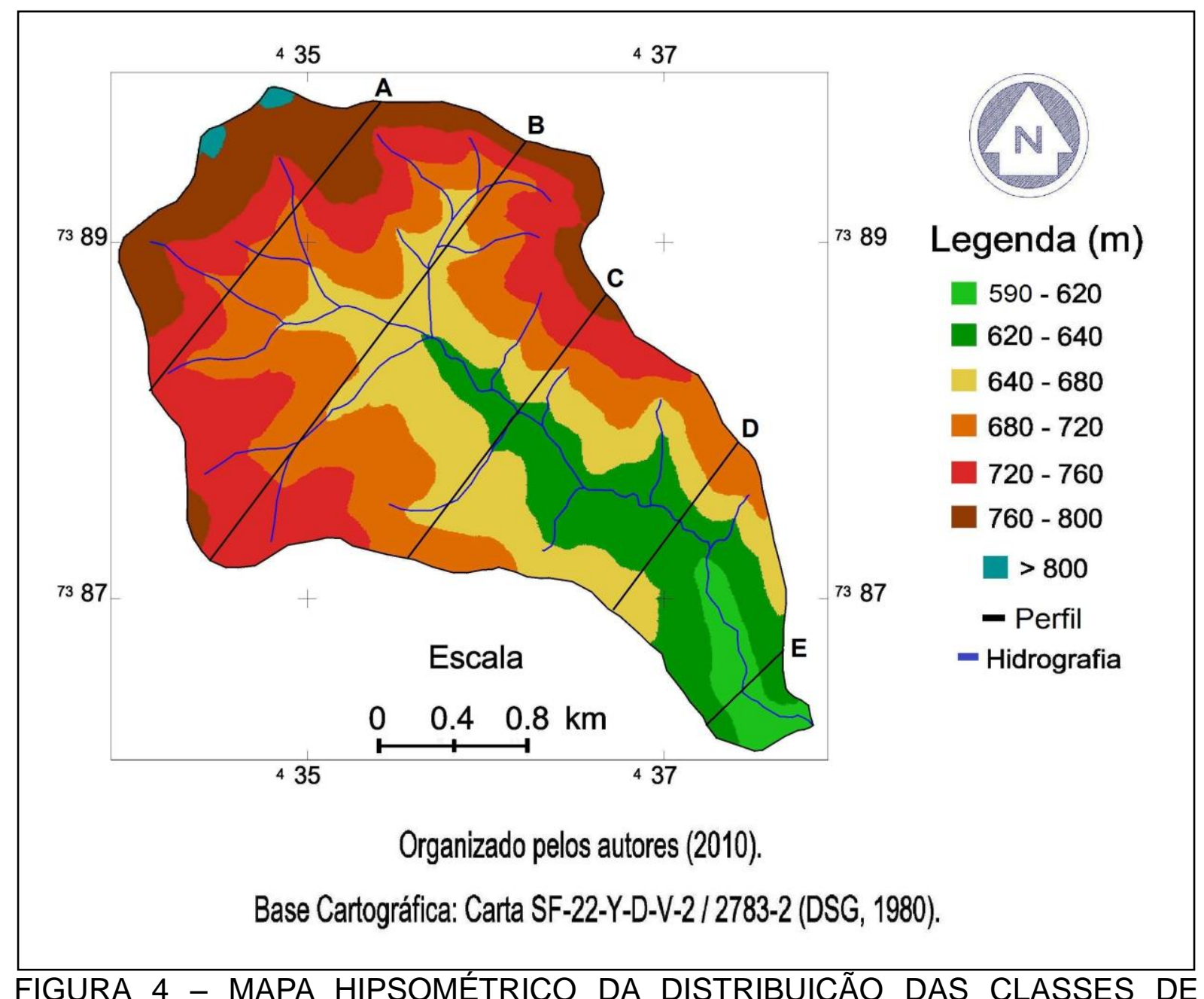

ALTITUDE DA BHCM

FIGURA 5 - PERFIS TRANSVERSAIS DA BHCM

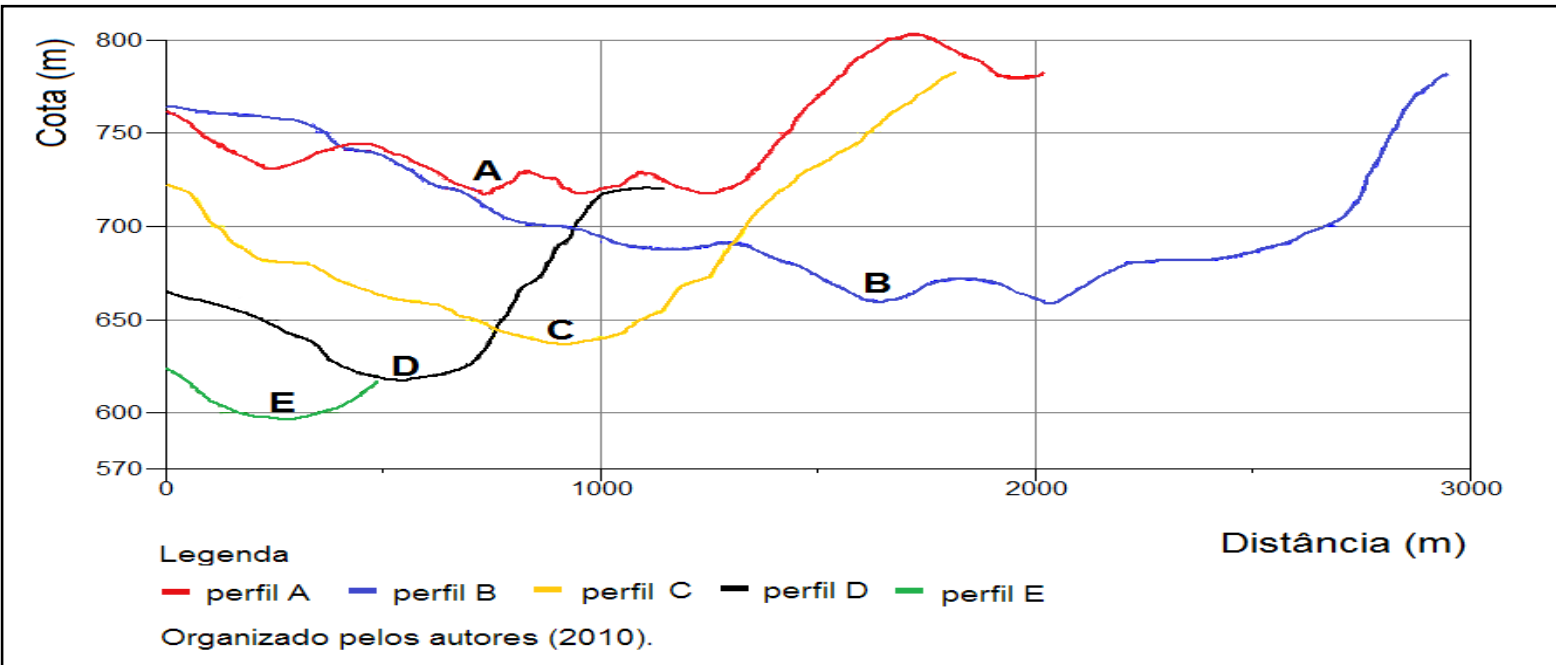

FONTE: Os autores (2010)

3.3 ASPECTOS CLINOGRÁFICOS 
O aspecto clinográfico, juntamente com a densidade da cobertura vegetal, tipo de solo, intensidade das chuvas e a ocupação antrópica tem fundamental influência nas taxas de escoamento superficial das águas da chuva, nos processos de erosão do solo, no assoreamento de rios e na ocorrência de inundações. O mapa de declividade é uma forma de representação quantitativa do comportamento espacial do relevo, e tem as mais diversas aplicações, especialmente nas áreas de geomorfologia e planejamento territorial, tanto para o cumprimento da legislação ambiental brasileira, quanto para garantir a eficiência das intervenções do homem no ambiente (KOFFLER, 1994; ROMANOVSKI, 2001).

A BHCM apresenta uma declividade expressiva com uma mediana de 13,8\%, sendo possível observar pela curva e mapa clinográfica (FIGURA 6 E 7 E TABELA 3).

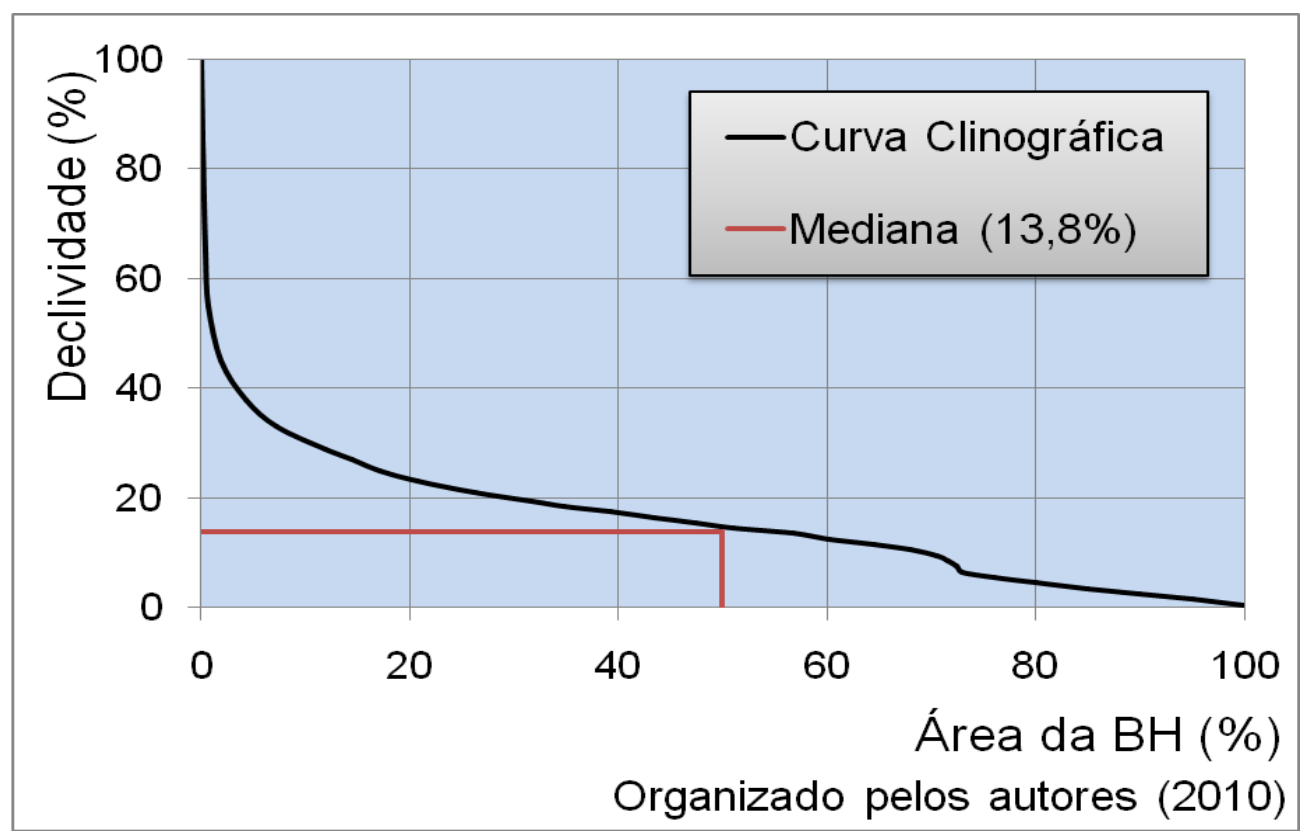

FIGURA 6 - CURVA CLINOGRÁFICA DA BHCM.

TABELA 3 - CLASSES DE DECLIVIDADE, ÁREA E PERCENTUAL DE CADA CLASSE NA BHCM 


\begin{tabular}{cccc}
\hline $\begin{array}{c}\text { Classe de declividade } \\
(\%)\end{array}$ & $\begin{array}{c}\text { Área em cada } \\
\text { classe }\left(\mathrm{km}^{2}\right)\end{array}$ & $\begin{array}{c}\text { Percentual } \\
\text { por classe }\end{array}$ & $\begin{array}{c}\text { Percentual } \\
\text { acumulado }\end{array}$ \\
\hline$<-06$ & 1,97 & 25,19 & 25,19 \\
$06-12$ & 0,73 & 9,34 & 34,53 \\
$12-20$ & 2,66 & 34,02 & 68,55 \\
$20-30$ & 1,55 & 19,82 & 88,37 \\
$>-30$ & 0,91 & 11,63 & 100,00 \\
Total & 7,82 & 100,00 & 100,00 \\
\hline
\end{tabular}

FONTE: Os autores (2010)

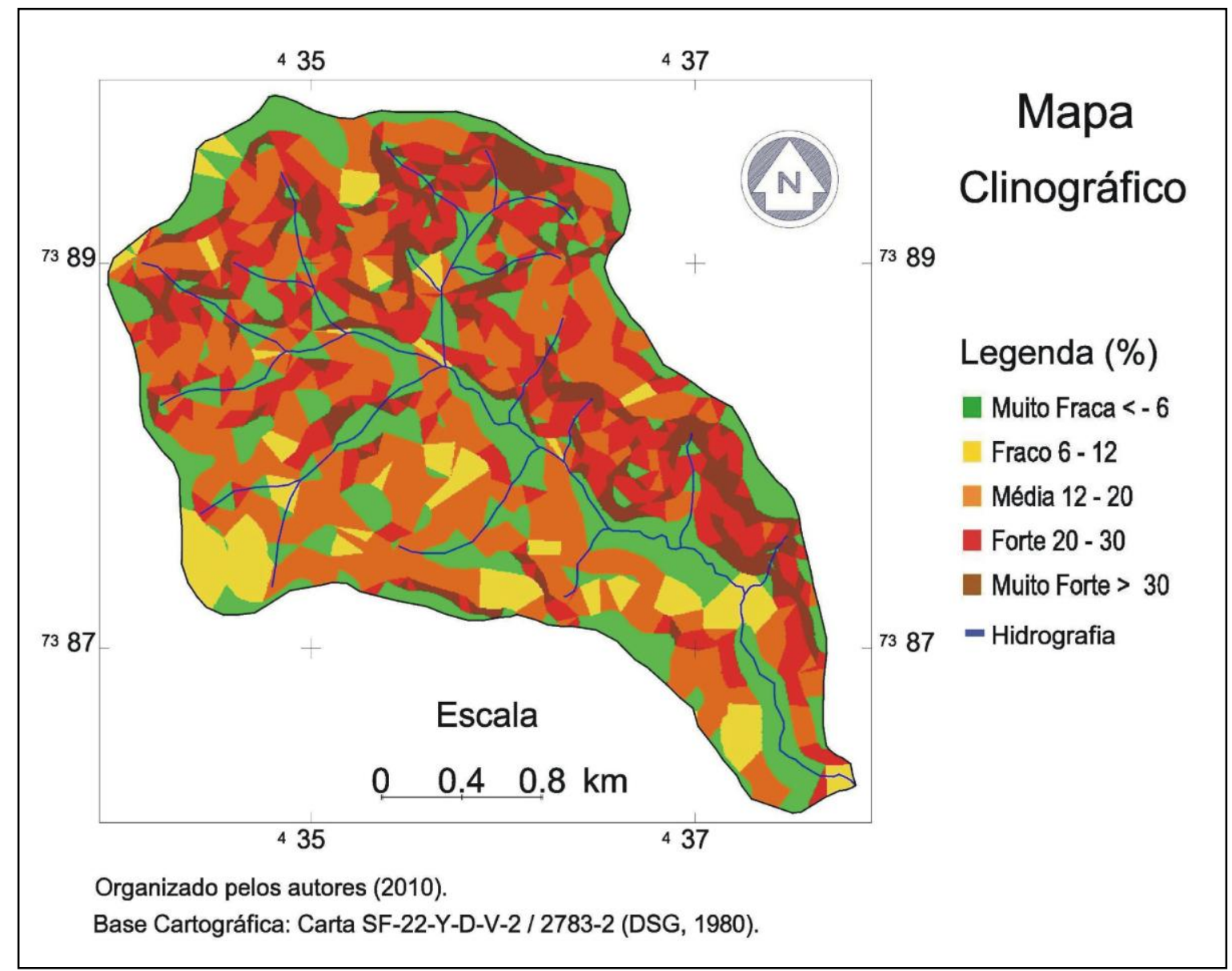

FIGURA 7 - MAPA DE DECLIVIDADE DA BHCM

A alta percentagem da declividade nas classes Forte e Muito Forte (aproximadamente $31,45 \%$ da área da $\mathrm{BH}$ ), associados à presença de nascentes 
locais, altos índices pluviométricos potencializa as vertentes íngremes a processos de movimento de massa, condicionando essas áreas como vulneráveis.

A ocorrência dessas formas se deve as peculiaridades geomorfológicas da referida bacia, tendo em vista os níveis de base locais e as condições climáticas favoráveis. Dessa forma é importante a conservação dessas áreas vulneráveis, a fim de minimizar os impactos na BHCM.

\section{CONSIDERAÇÕES FINAIS}

Nos levantamentos em campo verificou-se que a BHCM tem em sua montante um trecho ocupado pela área urbana de Jandaia do Sul e as vertentes à jusante pela agricultura e pecuária. Dessa forma, os processos naturais de precipitação - infiltração - percolação são alterados, potencializando impactos na dinâmica hidrogeomorfológica da BH. Essas alterações se devem em decorrência do processo de urbanização que implica na impermeabilização do solo e implantação de obras estruturais na rede de drenagem, aumentando o fluxo durante os episódios de chuvas intensas.

O relevo íngreme (principalmente no entorno das nascentes) associados à presença de áreas urbanas e os altos índices pluviométricos, favorecem os processos de movimento de massa, e o incremento de materiais tecnogênicos nos fundos de vales.

Dada as condições geomorfológicas da bacia e a localização da área urbana, cabe destacar à questão da recarga da água subterrânea, pois a cidade de Jandaia do Sul nasceu e se desenvolveu numa área divisor de águas, espigão onde se encontra as nascentes que formam a $\mathrm{BH}$, ou seja, numa região em que se dispões de pouca água para atender a demanda de seus diversos usos. Neste contexto cabe destacar que a BHCM é área de manancial que abaste a cidade, portanto o planejamento do uso e ocupação do solo é fundamental para o equilíbrio qualitativo e quantitativo dos recursos hídricos.

Assim pode-se concluir que naturalmente a morfometria da BHCM restringem áreas de atividades de uso do solo intensivo e expansão urbana nas áreas com declividades acentuadas, pois $31,45 \%$ das áreas da bacia apresentam 
declividades acima dos 20\%. A BH possui uma declividade mediana de $13,8 \%$, constituindo um relevo bastante dissecado com significativa densidade de drenagem $\left(2,07 \mathrm{~km} / \mathrm{km}^{2}\right)$. Portanto, a fim de manter em equilíbrios nos processos naturais da $\mathrm{BH}$ e não potencializar desajustes significativos da área, o uso do solo deve ser planejado e controlados nas áreas com relevo dissecado.

Por fim, conclui-se que os resultados obtidos com a análise dos aspectos morfométricos e trabalhos de campo aliados às técnicas de Geoprocessamento na BHCM demonstraram ser extremamente satisfatórios. Contudo, o presente trabalho não tem objetivo de finalizar as discussões referentes aos processos ambientais existentes na bacia. Pois a pesquisa proporcionou um diagnóstico preliminar, fornecendo subsídios para futuros trabalhos na área, afim de melhor analisar os processos naturais e antrópicos.

\section{REFERÊNCIAS}

BRASIL. Lei Federal no 4.771, de 15 de setembro de 1965. Estabelece o Codigo Florestal Brasileiro. Diário Oficial da República Federativa do Brasil. Brasilia, DF. 16 set. 1965.

CÂMARA, G.; SOUZA, R.; FREITAS, U.; GARRIDO e J. SPRING: Integrating Remote Sensing and GIS with Object-Oriented Data Modelling. Computers and Graphics, 15, 1996. p. 13-22.

CHRISTOFOLETTI, A. Geomorfologia. 2ª ed. São Paulo: Edgar Blücher, 1980. DSG (Diretoria de Serviços Geográficos do Exército), Carta Topográfica de Mandaguari, Folha SF.22-Y-D-V-3 MI2793/2, escala: 1: 50.000, 1르 ed. 1980.

FRITZSONS, E.; MANTOVANI, L. E.; e AGUIAR, A. V. Relação entre Altitude e Temperatura: uma contribuição ao zoneamento climático no estado do Paraná. Revista de Estudos Ambientais (REA) v.10, n. 1, 2008. p. 49-64.

HORTON, R. E. Erosional development of streams and their drainage basins: a hydrophysical approach to quantitative morphology. GeolSoc. Am. Bull. v.56, n.3, p.275-370, 1945.

IBGE (Instituto de Geografia e estatísticas), Carta Geológica, Folha de Londrina, Escala 1: 250.000, 2006. 
KOFFLER, N. F. Carta de declividade da bacia do rio Corumbatai para analise digital (SIG). Rio Claro: Boletim de Geografia Teorética, n. 19, v. 2, p. 167-182, 1994.

MAACK, R. Geografia Física do Estado do Paraná. 3a․ ed. Curitiba: Banco de Desenvolvimento do Paraná, Universidade Federal do Paraná, Instituto de Biologia e Pesquisa Tecnológica, 2002.

MIKICH, S. B. \& S. M. Silva, 2001. Composição florística e fenologia das espécies zoocoricas de remanescentes de Floresta Estacional Semidecidual no centro-oeste do Paraná, Brasil. Acta Botânica, Rio de Janeiro, 15 (1): 19-113.

MILANI, J. R.; CANALI, N. E. Analise morfométrica do complexo hidrográfico do rio matinhos por uma analise morfométrica. Curitiba: Revista RA'EGA, n.4, p. 139-152, 2000.

OLIVEIRA, E. D.; CUNHA, M. C.; VESTENA, L. R. e THOMAZ, E. L. Aspectos Morfométricos da Bacia Hidrográfica do Rio Cascavel, Guarapuava - PR. In: V SimpGeo (Simpósio Paranaense de Pós-Graduação e Pesquisa em Geografia, UFPR, Anais, 2010, 36-51 p.

ROMANOVSKI, Z. Morfologia e aspectos hidrológicos para fins de manejo da microbacia da Rua Nova, Viçosa-MG, para fins de manejo. 2001. 99f. Tese (Mestrado) - Universidade Federal de Viçosa, Viçosa, MG, 2001.

ROSS, J. L. S. Análise empírica da fragilidade dos ambientes naturais e antropizados. Revista do Departamento de Geografia, São Paulo, n.8 p.63-74, 1994.

STRAHLER, A. N. Quantitative analysis of watershed Geomorphology. Am. Geophys. Union Trans. 38 (6): 913-920, 1957.

SUGUIU, K. e BIGARELLA, J.J. Ambientes fluviais. 2a Ed. Florianópolis. Ed. UFSC. 1990. 183p.

TEODORO, V. L.; TEIXEIRA, D.; COSTA, D. J. L. e FULLER, B. B. O Conceito de Bacia Hidrográfica e a Importância da Caracterização Morfométrica para o Entendimento da Dinâmica Ambiental Local. In: REVISTA UNIARA: Revista do Centro Universitário de Araraquara, Araraquara/SP. n. 20, 2007, p. 137-156.

THOMAZ, E. L. Introdução ao monitoramento ambiental em cabeceira de drenagem urbano-rural. In: FERREIRA, Y. N. (org) Águas Urbanas: Memória, Gestão, Riscos e Regeneração. Londrina: Eduel, 2007.

TONELLO, K.C. Análise Hidroambiental da Bacia Hidrográfica da Cachoeira das Pombas, Guanhães, MG. 69p. Tese (Doutorado em Ciências Florestal) Universidade Federal de Viçosa, Viçosa, 2005. 
VILLELA, S. M. MATTOS, A. Hidrologia Aplicada. São Paulo, McGraw-Hill do Brasil, 1975. 245p.

(Recebido em 13.01.2011. Aceito em 11.03.2011) 